\title{
Nerve Microvessel Changes in Diabetes are Prevented by Aldose Reductase Inhibition
}

\author{
Timothy J. Benstead and Virgilio E. Sangalang
}

\begin{abstract}
Background: Despite the potential importance of endoneurial microvessel abnormalities in diabetic neuropathy, the pathogenesis of these abnormalities is incompletely understood. We wished to evaluate the effect of experimental diabetes on endoneurial microvessels and determine if an aldose reductase inhibitor alters any of the changes induced by diabetes. Methods: We compared streptozocin diabetic rats with and without aldose reductase inhibitor treatment to non-diabetic rats after 10 months of diabetes. Transverse microvessels from the mid-sciatic level were studied by electron microscopic morphometric evaluation. Results: Microvessel endothelial, pericyte, basement membrane and total mural area were greater in untreated diabetic animals than non-diabetic animals. Aldose reductase inhibitor treated diabetic animals had greater endothelial area and possibly pericyte area but not basement membrane or total mural area. Conclusions: This study demonstrates that endoneurial microvessel abnormalities can be detected in experimental diabetic neuropathy. Microvessel basement membrane thickening will be prevented by an aldose reductase inhibitor. One mechanism by which abnormal polyol pathway activity may contribute to diabetic neuropathy could be through damage to microvessels.
\end{abstract}

\begin{abstract}
RÉSUMÉ: Prévention des changements au niveau des microvaisseaux endoneuriaux par inhibition de l'aldose réductase dans le diabéte. Introduction: Malgré l'importance potentielle des anomalies des microvaisseaux endoneuriaux dans la neuropathie diabétique, leur pathogenèse n'est pas bien comprise. Notre but était d'évaluer l'effet du diabète expérimental sur les microvaisseaux endoneuriaux et de déterminer si un inhibiteur de l'aldose réductase modifie les changements induits par le diabète. Méthodes: Nous avons comparé des rats diabétiques depuis dix mois (diabète induit par la streptozotocine) avec et sans traitement par l'aldose réductase, à des rats non diabétiques. Nous avons procédé à une évaluation morphométrique par microscopie électronique des microvaisse aux au niveau sciatique moyen. Résultats: Les aires endothéliales, du péricyte, de la membrane basale et murale totale des microvaisseaux étaient plus grandes chez les animaux diabétiques non traités que chez les animaux non diabétiques. Chez les animaux diabétiques traités au moyen de l'inhibiteur de l'aldose réductase, l'aire endothéliale et possiblement l'aire du péricyte étaient plus étendues, mais l'aire de la membrane basale et l'aire murale totale n'étaient pas modifiées. Conclusions: Cette étude démontre que des anomalies des microvaisseaux endoneuriaux peuvent être détectées dans la neuropathie diabétique expérimentale. L'épaississement de la membrane basale des microvaisseaux peut être prévenu par un inhibiteur de l'aldose réductase. Le dommage causé aux microvaisseaux est un des mécanismes par lesquels une activité anormale de la voie polyole peut contribuer à la neuropathie diabétique.
\end{abstract}

Can. J. Neurol. Sci. 1995; 22: 192-197

Aldose reductase inhibition of polyol pathway activity can prevent electrophysiologic abnormalities in experimental diabetic neuropathy. ${ }^{1,2}$ Aldose reductase inhibitors have proven beneficial in some clinical trials for diabetic neuropathy. ${ }^{3.4}$ Structural improvements of nerve which may occur with use of aldose reductase inhibitors include increased rates of regeneration of nerve fibres, reduced paranodal demyelination, reduced segmental demyelination and reduced myelin wrinkling. ${ }^{4}$ However, the mechanism through which aldose reductase inhibition may ameliorate morphologic nerve fibre changes in advanced diabetic neuropathy is incompletely understood. One hypothesis is that hyperglycemia leads to sorbitol accumulation, ${ }^{5}$ myo-inositol reduction, ${ }^{6.7}$ and sodium-potassium ATPase reduction at the node of Ranvier. ${ }^{8}$ This sequence produces axo-glial dysjunction which may be the first structural abnormality of diabetic neuropathy. ${ }^{9-11}$
As axo-glial dysjunction advances the fibre damage and loss in diabetic neuropathy develops. Inhibiting sorbitol accumulation through aldose reductase inhibition may prevent this process. ${ }^{4.9}$

The polyol pathway hypothesis as it is currently understood does not encompass the large body of evidence that microangiopathy and the ischemic process play an important role in the pathogenesis of diabetic neuropathy. The pattern of nerve fibre damage and loss suggests an ischemic process ${ }^{12-15}$ and the severity

From the Departments of Medicine (T.J.B.) and Pathology (V.E.S.), Dalhousie University, Halifax.

RECEIVED DECEMBER 21, 1993. ACCEPTED IN FINAL FORM JANUARY 6, 1995.

Reprint requests to: Dr. Timothy J. Benstead, Division of Neurology, Department of Medicine, Dalhousie University, Victoria General Hospital, Halifax, Nova Scotia, Canada B3H 2 Y9 
of microangiopathy has been statistically associated with severity of nerve fibre alteration. ${ }^{16-18}$

To further develop the polyol pathway hypothesis we were interested in evaluating a potential link between polyol pathway disturbance and endoneurial microvessel abnormalities. In particular we wished to determine if aldose reductase inhibition reduces the thickening of any of the microvessel wall components seen in diabetic neuropathy. Aldose reductase activity is found in endothelial cells of microvessels in nerves and other tissues. ${ }^{5.19}$ Aldose reductase inhibition has been shown to prevent basement membrane thickening in experimental diabetic retinopathy. ${ }^{20,21}$ Experimental models of diabetic endoneurial microangiopathy have been infrequently studied ${ }^{22}$ and the effect of pharmacological manipulation has not been reported. In this study we determined that endoneurial microangiopathy can be demonstrated in experimental diabetes and long term use of an aldose reductase inhibitor can prevent some microangiopathic changes.

\section{Materials AND MethodS}

Male Sprague-Dawley rats at age 3 months were divided into 3 groups. Two groups had diabetes induced by intraperitoneal injection of streptozocin $50 \mathrm{mg} / \mathrm{kg}$. One group of diabetic animals ( $\mathrm{n}=4$, onset weight $340.3 \pm 7.3 \mathrm{~g}$ ) was not treated. The second diabetic group $(\mathrm{n}=6,347.0 \pm 13.2 \mathrm{~g})$ received the aldose reductase inhibitor Statil $25 \mathrm{mg} / \mathrm{kg}$ (ICI Pharma) mixed into the daily feed of rat chow from the onset of diabetes. This dose of Statil has been previously demonstrated to inhibit aldose reductase activity in experimental diabetic neuropathy, normalizing nerve sorbitol levels and ameliorating nerve conduction velocity abnormalities in diabetic rats. ${ }^{23}$ The third group of animals did not have diabetes induced and did not receive any medication $(n=6,343.7 \pm 15.7 \mathrm{~g})$. The animals were raised on shavings in polypropylene cages and given unlimited water. Blood glucose and weight were monitored in all 3 groups at regular intervals. Glucose was measured on capillary blood using a glucometer after an overnight fast. Diabetes was defined as animals with blood glucose measurements greater than $17 \mathrm{mmol} / \mathrm{L}$ throughout the duration of the study.

At 10 months following induction of diabetes the animals were anaesthetized with sodium pentobarbital $50 \mathrm{mg} / \mathrm{kg}$ and the right sciatic nerve was exposed taking care not to damage nerve vessels and fixed in situ for 17 minutes with $4 \%$ glutaraldehyde in $0.025 \mathrm{M}$ cacodylate buffer at $\mathrm{pH} 7.39$. The sciatic nerve was removed from the level of the sciatic notch to its distal branches and placed in $2.5 \%$ glutaraldehyde in $0.025 \mathrm{M}$ cacodylate at $\mathrm{pH}$ 7.39 for 24 hours. Ten millimetres distal to the proximal cut end of the sciatic nerve a transverse block of nerve was cut and washed in cacodylate buffer and additionally fixed in $2 \%$ osmium tetroxide in buffer and embedded into epoxy. The blocks were embedded with proximal end up. This position along the sciatic nerve was approximately midpoint between the sciatic notch and the branching of the sciatic nerve near the knee. The midsciatic level has been shown in previous studies to represent a region where ischemic changes may be maximal in lower limb diabetic neuropathy ${ }^{13}$ and other ischemic processes. ${ }^{24.25}$

Transverse semi-thin $(0.75 \mu \mathrm{m})$ sections of the blocks were cut and stained with methylene blue. These sections were examined by light microscopy. Thin sections $(0.1 \mu \mathrm{m})$ of the entire transverse block were cut and stained with uranyl acetate and lead citrate. Electron micrographic analysis was then performed for morphometric evaluation of endoneurial microvessels. For each animal a single grid of thin sections from the transverse block was scanned for all microvessels. The grid usually contained between 2 to 3 consecutive thin sections. A systematic $x, y$ traverse of the thin sections was used to ensure all microvessels present were sampled. Electron micrographs were prepared of all endoneurial microvessels encountered in the $x, y$-traverse of thin sections. These micrographs were enlarged to final magnifications of approximately X6000 for large and X10,000 for small microvessels. If duplicate microvessels from the consecutive thin sections were photographed they were discarded. The group of microvessels analysed in each animal represented as many microvessels as could be found at a single transverse level. This method was used to ensure the measured values of microvessel components was as close to the true average for the animal at the nerve level evaluated.

The morphometric methods have been previously described ${ }^{26}$ including the method of tracing elements of the microvessel. The borders of the vessel lumen (LA), outer endothelial border $(O E B)$, pericyte cell body and processes $(P)$ and outer vessel border (OVB) were traced. A programmable digitizing tablet was used to determine the area within the space circumscribed by these borders. The endothelial area (OEB-LA), basement membrane area [OVB - $(\mathrm{P}+\mathrm{OEB})$ ] and mural area (OVB-LA) were calculated. The number of endothelial nuclei per vessel and pericyte nuclei per vessel were counted.

Values for comparison are expressed as mean \pm standard deviation (SD). The mean values compared are the means of the groups which are obtained by averaging the mean values from each animal. To determine if an overall difference in the size of the microvessel wall was present among the groups, the mural area of the 3 groups was compared using ANOVA one way analysis. Two-sampled t-tests for unpaired samples (95 percent confidence limits) were then used to assess separate components of the vessel wall as well as other microvessel features of interest including lumen area, endothelial nuclei per vessel, pericyte nuclei per vessel and total vessel area. Statistical difference was compared between the untreated diabetic and non-diabetic groups, the Statil treated diabetic and non-diabetic groups and the Statil treated diabetic and untreated diabetic groups.

\section{RESULTS}

All diabetic rats had persistent blood glucose measurements greater than $20 \mathrm{mmol} / \mathrm{L}$. The diabetic rats without Statil developed dense cataracts and with Statil only slight or no cataracts. Weights of animals in the untreated diabetic group $(454.5 \pm 18.0$ gm, $p=0.0005)$ and Statil treated diabetic group $(435.3 \pm 60.9$, $\mathrm{p}=0.0005$ ) were significantly lower at the end of the study than the non-diabetic group $(705.0 \pm 30.2 \mathrm{gm})$ consistent with what is anticipated in experimental diabetic neuropathy. ${ }^{27}$

There was no obvious alteration of endoneurial microvessel appearance at light microscopic magnification level. Microvessels examined by electron microscopy were occasionally closed in the diabetic nerves. The microvessel wall gave the appearance of thickening in diabetic nerves which was confirmed by morphometric analysis (Figures 1-3). Using ANOVA the mural area between the 3 groups was different $(p<0.05)$. There did not appear to be other structural differences of mural 


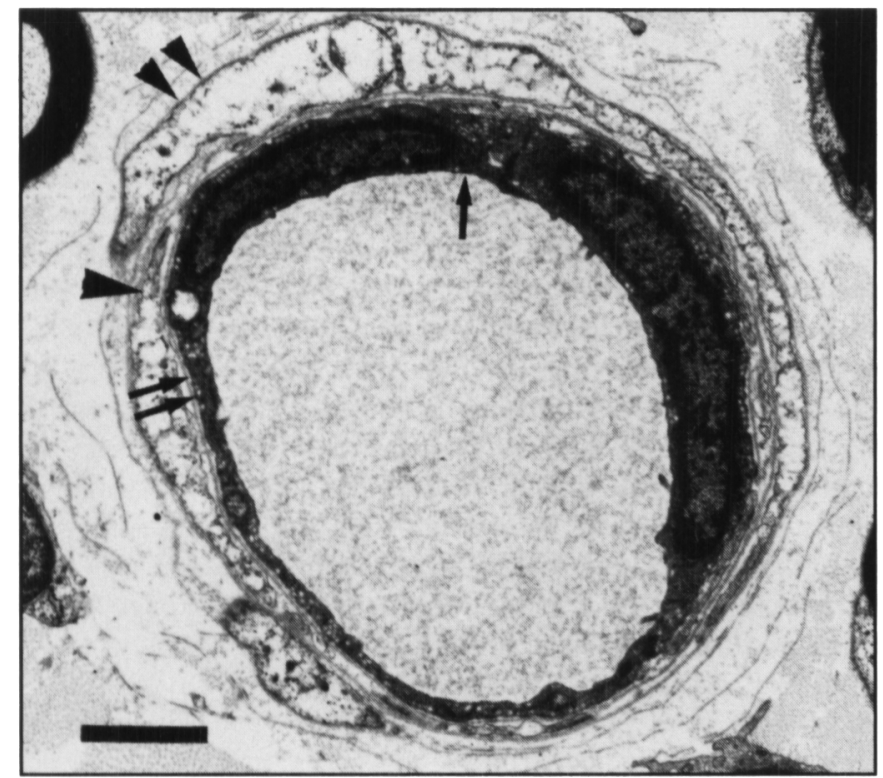

Figure 1: Electron micrograph of endoneurial microvessel from the tibial nerve of a non-diabetic rat. Measurements were made of the vessel lumen (arrow), outer endothelial border (double arrows), pericyte cell body and processes (arrowhead) and outer vessel border (double arrowheads). The size of mural components were calculated from these measurements. Stained with uranyl acetate and lead citrate. Calibration bar $=2.0 \mu \mathrm{m}$

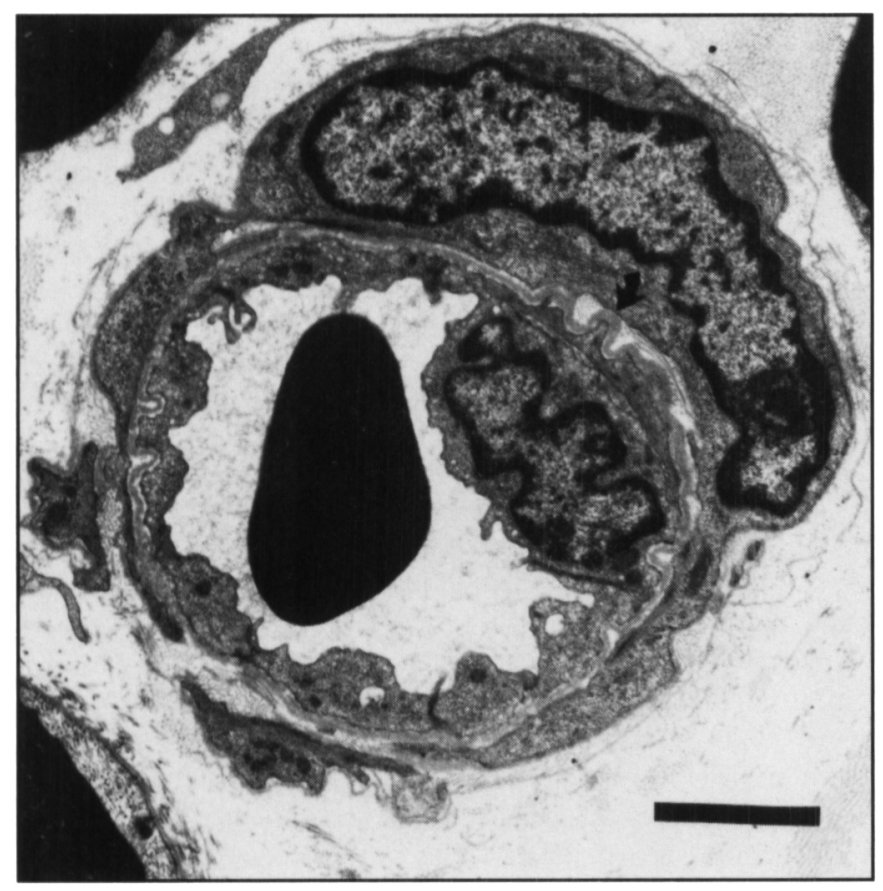

Figure 2: Endoneurial microvessel from a diabetic rat. On average the size of all components of the vessel wall including endothelial cell, pericyte cell and basement membrane were significantly greater than nondiabetic rats. The basement membrane between the endothelial and pericyte cells in this vessel appears thickened. Stained with uranyl acetate and lead citrate. Calibration bar $=2.0 \mu \mathrm{m}$.

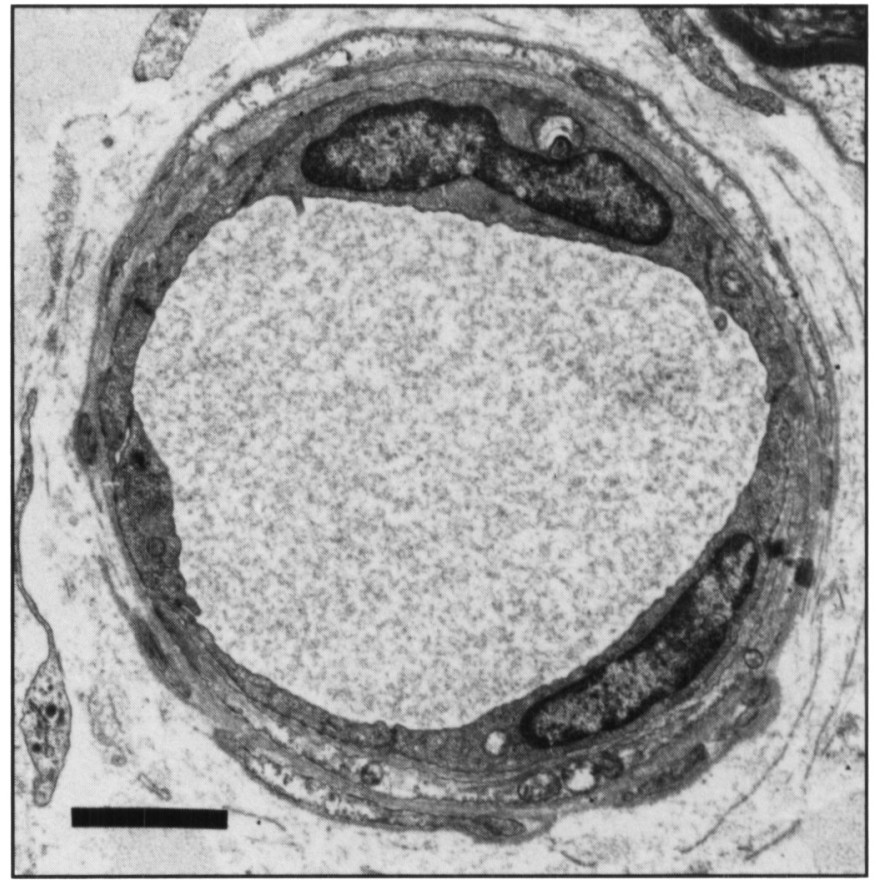

Figure 3: Endoneurial microvessel from a Statil treated diabetic rat. Mean endothelial cell area was greater in Statil treated diabetic rats than non-diabetic animals and the mean pericyte area was also greater approaching significant levels. The mean basement membrane area measurement for the Statil treated group was not greater than in the non-diabetic group. Stained with uranyl acetate and lead citrate. Calibration bar $=2.0 \mu \mathrm{m}$.

elements in diabetic nerve microvessels. Excess pericyte degeneration or degeneration of endothelial organelles was not seen. Tight junctions between endothelial cells appeared preserved.

Morphometric measurements were made of multiple microvessels from each animal, all obtained from sections at the same transverse level. The mean number of microvessels measured per rat was not different between groups (Table). The microvessel lumen area and total vessel area were largest in the diabetic animals but mean values were not significantly different between groups. As compared to non-diabetic controls all components of the vessel wall in untreated diabetic nerves were increased in size including endothelial area $(P=0.005)$, pericyte area $(P=0.038)$, basement membrane area $(P=0.024)$ and total mural area $(P=0.005)$. The increased size of wall components ranged from an increase of $31 \%$ for pericyte area, $35 \%$ for endothelial area and $40 \%$ for basement membrane area. In the Statil treated diabetic group the endothelial area was $25 \%$ greater than the control group which was significant $(P=0.016)$. Pericyte area was $25 \%$ greater than controls which reached borderline significance $(P=0.051)$. There was no significant difference in the basement membrane area of Statil treated diabetic nerves and control nerves. The overall mural area of the Statil group was not significantly different than control. The number of endothelial and pericyte nuclei per vessel was not different in either diabetic group compared to controls suggesting that the endothelial and pericyte changes are due to increase in cell size and not cell number.

Comparisons between the Statil treated and untreated diabetic groups demonstrated that for all measurements except basement 
Table: Morphometric Comparisons of Electron Micrographs of Endoneurial Microvesels From Non-Diabetic, Diabetic and Statil Treated Diabetic Rat Tibial Nerve.

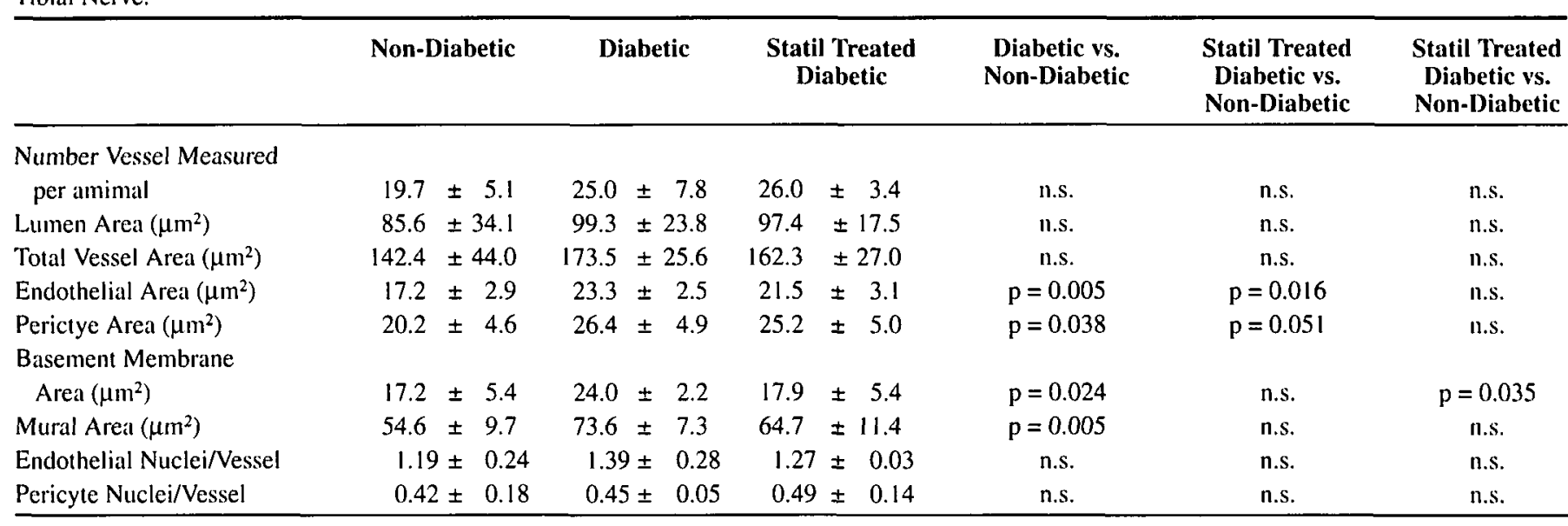

Values are mean $\pm \mathrm{SD}$ of nerve means.

membrane area no differences were found. The Statil treated animals developed less thickening of basement membrane than untreated diabetics $(\mathrm{p}=0.035)$.

\section{Discussion}

The present study demonstrates that endoneurial microvessel abnormalities develop after 10 months of experimental diabetic neuropathy. Experimental diabetic microangiopathy has not been frequently reported. ${ }^{22}$ The model used in the current study proved helpful for studying the effect of pharmacological manipulation on diabetic microangiopathy. Due to the potential importance of microvessels in the pathogenesis of diabetic neuropathy the experimental model of microangiography demonstrated here will be very useful for evaluating future possible treatment strategies.

Endoneurial microvessels in chronic clinical diabetic neuropathy demonstrate thickening of mural elements including endothelial cells, pericyte cells and basement membrane. ${ }^{16,17,28,29}$ This results in increased rates of microvessel closure. ${ }^{18}$ The alterations of the microvessel wall and the rates of vessel closure ${ }^{18}$ are statistically associated with the severity of nerve fibre change in diabetic neuropathy. ${ }^{16-18,28}$ The pattern of myelinated fibre damage and loss is consistent with the pattern of an ischemic neuropathy. ${ }^{12-14}$ The endoneurial microenvironment demonstrates reduced nerve blood flow and decreased oxygen tension in experimental diabetic neuropathy ${ }^{30.31}$ and patients with diabetic neuropathy. ${ }^{32.33}$ Nerve conduction velocity slowing and myelin abnormalities develop in rats reared in a hypoxic environment. ${ }^{34,35}$ Oxygen supplementation of animals with experimental diabetic neuropathy will improve electrophysiologic abnormalities. ${ }^{36}$ These morphologic and physiologic data have led to the conclusion that endoneurial microvessel abnormalities may play an important role in the development of diabetic neuropathy.

The pattern of microvessel change in the present experimental model of diabetes correlates well with what is seen in clinical diabetic neuropathy. Thickening of the three components of the endoneurial microvessel wall was found including endothelium, pericytes and basement membrane. Mean total vessel area was greatest in the diabetic group raising the concern that basement membrane area increase may at least in part reflect the measurement of larger vessels in that group. However, the total vessel area was not significantly different between groups and the method of selecting microvessels for measurement was chosen to avoid bias toward evaluating larger or smaller microvesels in any particular animal. The results should reasonably represent the mean values from each animal making comparisons between groups valid.

Only a few vessels were closed in the experimental model, but it is possible that end stage microvessel abnormalities may require much longer duration diabetes than the 10 months of this study. Statil prevented basement membrane thickening in endoneurial microvessels similar to what has been demonstrated in retinal microvessels in diabetes treated with an aldose reductase inhibitor. ${ }^{20,21}$ Statil may have a beneficial effect in preventing changes in other vessel wall structures as the pericytc change in Statil treated animals was of borderline significance. It is not certain what specific effect an alteration of each mural component would have on the vessel function, though oxygen transport, nutrient transport and the blood nerve barrier would be at risk for dysfunction by microvessel changes.

When the oxygen transport function of microvessels is interrupted a number of hypoxic consequences will occur in the nerve. Some of these may occur immediately but delayed secondary effects may develop. It has been shown that capillary closure will directly damage nerve fibres. Experimental occlusion of endoneurial microvessels with microspheres produces a pattern of myelinated fibre alteration similar to what is found in diabetic and other ischemic neuropathies. ${ }^{25}$ Ischemia produces marked changes in nerve structures other than myelinated fibres such as the perineurium ${ }^{37}$ and the endoneurial microvessel itself. ${ }^{26}$ The endothelial cells of the microvessel are particularly susceptible to ischemic damage. This means that once microvessel pathology has been initiated a progressively worsening cycle may develop of hypoxic induced microvessel damage, worsened hypoxia and greater microvessel damage.

Microvessel changes could also contribute to development of an ischemic microenvironment through reduced prostacyclin synthesis in endoneurial microvessels ${ }^{38}$ leading to increased platelet aggregation, ${ }^{39}$ increased microvessel tone ${ }^{39}$ and reduced 
nerve blood flow. As well, thickened rigid microvessel walls may be incapable of normal squeezing of red blood cells to assist oxygen exchange. ${ }^{40.41}$ Vasodilation has been reported in acute diabetic neuropathy ${ }^{42}$ and is an early indicator of abnormal vasoreactivity. In this model of chronic diabetic neuropathy lumen area was not altered suggesting that vasodilation is no longer present at this stage.

Regardless of how and to what extent abnormal microvessels contribute to the development of diabetic neuropathy it has not yet been established how microvessels are altered in the first instance. The present study provides one potential link between microvessel abnormalities and the metabolic disruption of the nerve microenvironment that is set in motion by hyperglycemia. During hyperglycemia the polyol pathway actively converts glucose to sorbitol through the enzyme aldose reductase. This metabolic process may be responsible for several complications of diabetes. ${ }^{43,44}$ Increased polyol activity in experimental diabetic neuropathy leads to depletion of tissue myo-inositol, ${ }^{6.7}$ though in human diabetic neuropathy reduced myo-inositol is not always found. ${ }^{45}$ Voltage clamp studies show sodium channel activity at the node of Ranvier is impaired ${ }^{46}$ by abnormal sodium potassium ATPase activity that can be attributed to myo-inositol reduction. ${ }^{8}$ Abnormalities of nodal function could slow nerve conduction velocity which is the first electrophysiologic abnormality found in experimental diabetic neuropathy. As well, axoglial dysjunction present in diabetic neuropathy may be the result of the metabolic abnormalities at the node that occur in early diabetes. ${ }^{10}$ This structural nodal abnormality may explain why the nerve conduction abnormalities in established diabetic neuropathy are poorly reversible despite correction of the hyperglycemia.

The current study shows that microvessels are also affected by abnormal polyol pathway activity. An important link between aldose reductase activity and microvessel alteration may result from abnormalities in nitric oxide metabolism due to increased polyol production. Nitric oxide is a potent vasodilator. ${ }^{42}$ Aldose reductase activity competes with nitric oxide synthetase for $\mathrm{NADPH}^{47}$ which may decrease production of this vasodilator over time. However, in the acute stages of diabetes an increased $\mathrm{NADH} / \mathrm{NAD}^{+}$ratio promotes increased nitric oxide production. ${ }^{42}$ These changes in vasoreactivity may contribute to chronic morphologic microvessel abnormalities in diabetic neuropathy. The morphologic abnormalities of microvessels similar to myelinated fibre alterations may be poorly reversible in established diabetic neuropathy.

In addition to polyol pathway abnormalities, other metabolic factors may play a role in the development of diabetic neuropathy. Non-enzymatic glycation of proteins contributes to vessel abnormalities through increased protein cross linking in the vessel wall..$^{48.49}$ This effect appears to be largely independent of aldose reductase activity ${ }^{49}$ though polyol pathway abnormalities may indirectly promote glycation by increasing fructose levels. As well, nitric oxide may be linked to glycation as aminoguanidine inhibits the production of both. ${ }^{50}$ Further work is necessary to determine how these various factors interact to produce microvessel abnormalities in diabetic neuropathy.

It is possible that microvessel abnormalities in diabetic neuropathy develop secondary to the metabolic disturbance but do not have any pathogenic role in the development of myelinated fibre alteration. Similar microvessel changes have been reported in inherited neuropathies which are not felt to have any ischemic pathogenic mechanism. ${ }^{51}$ Metabolic abnormalities could damage axons and Schwann cells directly ${ }^{9-11,52,53}$ with microvessels as innocent bystanders being affected by the metabolic changes that lead more directly to fibre damage. However, the results of many studies to date support the presence of some ischemic process affecting diabetic nerve. The strong link demonstrated between microvessel changes and the progression of neuropathy makes the possibility that microvessels are not at all important to the development of diabetic neuropathy unlikely to be entirely correct. It would seem more likely that microangiopathy contributes to diabetic neuropathy as one component of a multifactorial process that includes hypoxia and other direct metabolic effects on myelinated fibres.

In experimental diabetic neuropathy the morphologic changes of myelinated fibres are not as striking as those in well established clinical diabetic neuropathy. Changes in the region of the node of Ranvier, ${ }^{9-11}$ axonal shrinkage ${ }^{52}$ and Schwann cell injury ${ }^{53}$ occur in experimental and clinical diabetic neuropathy but it is unclear how the mild morphologic changes of experimental diabetic neuropathy relate to the severe multifocal fibre damage and loss in clinical diabetic neuropathy. Short term experimental diabetic neuropathy likely does not completely model what occurs in long term clinical diabetic neuropathy. The current study demonstrates that vascular changes can be detected after 10 months of experimental diabetic neuropathy. A much longer period of time may be required for these vascular changes to advance to the point where they will produce sufficient ischemia in the nerve to lead to multifocal nerve fibre loss. Therefore, the morphologic alterations of microvessels in experimental diabetic neuropathy of 10 months duration may be as important a marker of nerve damage from diabetes as the early structural changes in myelinated fibres. Experimental microvessel changes may also be an important target for assessment of therapeutic intervention when the aim of intervention is to prevent late stage ischemic myelinated fibre alteration.

\section{ACKNOWLEDGEMENT}

The authors thank Marina Payson and Debbie Sheppard for their expert technical and secretarial assistance. Support for this project was received from ICI Pharma.

\section{REFERENCES}

1. Mayer JH, Tomlinson DR. Prevention of defects of axonal transport and nerve conduction velocity by oral administration of myoinositol or an aldose reductase inhibitor in streptozotocin-diabetic rats. Diabetologia 1983; 25:433-438.

2. Yue DK, Hanwell MA, Satchell PM, Turtle JR. The effect of aldose reductase inhibition on motor nerve conduction velocity in diabetic rats. Diabetes 1982; 31: 789-794.

3. Judzewitsch RG, Jaspan JB, Polonsky KS, et. al. Aldose reductase inhibition improves nerve conduction velocity in diabetic patients. N Engl J Med 1983; 308: 1 19-125.

4. Sima AAF, Bril V, Nathaniel V, et. al. Regeneration and repair of myelinated fibers in sural-nerve biopsy specimens from patients with diabetic neuropathy treated with sorbinil. $\mathrm{N}$ Engl J Med 1988; $319: 548-555$.

5. Gabbay KH, O'Sullivan JB. The sorbitol pathway: enzyme localization and content in normal and diabetic nerve and cord. Diabetes 1968; 17: 239-243.

6. Hale PJ, Nattrass M, Silverman SH, et. al. Peripheral nerve concentrations of glucose, fructose, sorbitol and myoinositol in diabetic and non-diabetic patients. Diabetologia 1987; 30: 464-467. 
7. Greene DA, Lewis RA, Lattimer SA, Brown MJ. Selective effects of myo-inositol administration on sciatic and tibial motor nerve conduction parameters in the streptozocin diabetic rat. Diabetes 1982; 31: 573-578.

8. Greene DA, Lattimer SA. Impaired rat sciatic nerve sodium-potassium adenosinetriphosphate in acute streptozotocin diabetes and its correction by dietary myo-inositol supplementation. J Clin Invest 1983; 72: 1058-1063.

9. Greene DA, Chakrabarti S, Lattimer SA, Sima AA. Role of sorbitol accumulation and myo-inositol depletion in paranodal swelling of large myelinated nerve fibers in the insulin-deficient spontaneously diabetic bio-breeding rat: reversal by insulin replacement, an aldose reductase inhibitor and myo-inositol. J Clin Invest 1987; 79: 1479-1485.

10. Sima AA, Lattimer SA, Yagihashi S, Greene DA. Axo-glial dysjunction: a novel structural lesion that accounts for poorly reversible slowing of nerve conduction in the spontaneously diabetic bio-breeding rat. J Clin Invest 1986; 77: 474-484.

11. Sima AAF, Brismar T. Reversible diabetic nerve dysfunction: structural correlates to electrophysiological abnormalities. Ann Neurol 1985; 18: 21-29.

12. Dyck PJ, Lais A, Karnes JL, O'Brien P, Rizza R. Fiber loss is primary and multifocal in sural nerves in diabetic polyneuropathy. Ann Neurol 1986; 19: 425-439.

13. Dyck PJ, Karnes JL, O'Brien P, et al. The spatial pattern of fiber loss in diabetic polyneuropathy suggests ischemia. Ann Neurol 1986; 19: 440-449

14. Johnson PC, Doll SC, Cromey DW. Pathogenesis of diabetic neuropathy. Ann Neurol 1986; 19:450-457.

15. Raff MC, Sangalang V, Asbury AK. Ischemic mononeuropathy multiplex associated with diabetes mellitus. Arch Neurol 1968; 18: 487-499.

16. Malik RA, Newrick PG, Sharma AK, et al. Microangiopathy in human diabetic neuropathy: relationship between capillary abnormalities and the severity of neuropathy. Diabetologia 1989; 32: $92-102$

17. Yasuda H, Dyck PJ. Abnormalities of endoneurial microvessels and sural nerve pathology in diabetic neuropathy. Neurology 1987; 37: $20-28$

18. Dyck PJ, Hansen S, Karnes J, et al. Capillary number and percentage closed in human diabetic sural nerve. Proc Natl Acad Sci USA 1985; 82: 2513-2517.

19. Chakrabarti S, Sima AAF, Nakajima T, Yagihashi S, Greene DA Aldose reductase in the $\mathrm{BB}$ rat: isolation, immunological identification and localization in the retina and peripheral nerve. Diabetologia 1987; 30: 244-251.

20. Robison WG, Kador PF, Kinoshita JH. Retinal capillaries: basement membrane thickening by galactosemia prevented with aldose reductase inhibitor. Science 1983; 221: $1177-1179$.

21. Frank RN, Keirn RJ, Kennedy A, Frank KW. Galactose-induced retinal capillary basement membrane thickening: prevention by sorbinil. Invest Ophthalmol Vis Sci 1983; 24: 1519-1524.

22. Powell HC, Myers RR. Axonopathy and microangiopathy in chronic alloxan diabetes. Acta Neuropathol (Berl) 1984; 65: 128-137.

23. Stribling D, Mirrlees DJ, Harrison HE, Earl DCN. Properties of ICI 128,436, a novel aldose reductase inhibitor, and its effects on diabetic complications in the rat. Metabolism 1985; 34: 336-344.

24. Sladky JT, Greenberg JH, Brown MJ. Regional perfusion in normal and ischemic rat sciatic nerves. Ann Neurol 1985; 17: 191-195.

25. Nukada H, Dyck PJ. Microsphere embolization of nerve capillaries and fiber degeneration. Am J Pathol 1984; 115: 275-287.

26. Benstead TJ, Sangalang VE, Dyck PJ. Acute endothelial swelling is induced in endoneurial microvessets by ischemia. J Neurol Sci 1990; $99: 37-49$.

27. Sharma AK, Bajada S, Thomas PK. Influence of streptozotocininduced diabetes on myelinated nerve fibre maturation and on body growth in the rat. Acta Neuropathol (Berl) 1981; 53: 257-265.

28. Britland ST, Young RJ, Sharma AK, Clarke BF. Relationship of endoneurial capillary abnormalities to type and severity of diabetic neuropathy. Diabetes 1990; 39: 909-913.
29. Williams E, Timperley WR, Ward JD, Duckworth T. Electron microscopical studies of vessels in diabetic peripheral neuropathy. J Clin Pathol 1980; 33: 462-470.

30. Low PA, Nukada H, Schmelzer JD, Tuck RR, Dyck PJ. Endoneurial oxygen tension and radial topography in nerve edema. Brain Res 1985; 341: 147-154.

31. Tuck RR, Schmelzer JD, Low PA. Endoneurial blood flow and oxygen tension in the sciatic nerves of rats with experimental diabetic neuropathy. Brain 1984; 107: 935-950.

32. Boulton AJM, Scarpello JHB, Ward JD. Venous oxygenation in the diabetic neuropathic foot: evidence of arteriovenous shunting? Diabetologia 1982; 22: 6-8.

33. Newrick PG, Wilson AJ, Jakubowski J, Boulton AJM, Ward JD Sural nerve oxygen tension in diabetes. $\mathrm{Br}$ Med J 1986; 293 1053-1054.

34. Low PA, Schmelzer JD, Ward KK, Yao JK. Experimental chronic hypoxic neuropathy: relevance to diabetic neuropathy. Am J Physiol 1986; 25l: E94-E99.

35. Benstead TJ, Dyck PJ, Low P. Chronic hypoxia induces selective maldevelopment of peripheral myelin in rat. J Neuropathol Exp Neurol 1988; 47: 599-608.

36. Low PA, Tuck RR, Dyck PJ, Schmelzer JD, Yao JK. Prevention of some electrophysiologic and biochemical abnormalities with oxygen supplementation in experimental diabetic neuropathy. Proc Natl Acad Sci USA 1984; 81: 6894-6898.

37. Benstead TJ, Dyck PJ, Sangalang V. Inner perineurial cell vulnerability in ischemia. Brain Res 1989; 489: 177-181.

38. Ward KK, Low PA, Schmelzer JD, Zochodne DW. Prostacyclin and noradrenaline in peripheral nerve of chronic experimental diabetes in rats. Brain 1989; 112: 197-208.

39. Weksler BB, Marcus AJ, Jaffe EA. Synthesis of prostaglandin 12 (prostacyclin) by cultured human and bovine endothelial cells. Proc Nat] Acad Sci USA 1977; 74: 3922-3926.

40. Branemark P-L, Lindstrom J. Shape of circulating blood corpuscles. Biorheology 1963; 1: 139-142.

41. Guest MM, Bond TP, Cooper RG, Derrick JR. Red blood cells: change in shape in capillaries. Science $1963 ; 142: 1319-1321$.

42. Williamson JR, Chang K, Frangos M, et al. Hyperglycemic pseudohypoxia and diabetic complications. Diabetes 1993; 42: 801-813.

43. Kador PF, Kinoshita JH. Role of aldose reductase in the development of diabetes-associated complications. Am J Med 1985; 79 (Suppl 5A): 8-12.

44. Hu T-S, Datiles M, Kinoshita JH. Reversal of galactose cataract with sorbinil in rats. Invest Ophthalmol Vis Sci 1983; 24: 640-644.

45. Dyck PJ, Zimmerman BR, Vilen TH, et. al. Nerve glucose, fructose, sorbitol, myo-inositol, and fiber degeneration and regeneration in diabetic neuropathy. $\mathrm{N}$ Engl J Med 1988; 319: 542-548.

46. Brismar T, Sima AAF. Changes in nodal function in nerve fibers of the spontaneously diabetic BB-Wistar rat. Potential clamp analysis. Acta Physiol Scand 1981; 113: 499-506.

47. Nathan $C$. Nitric oxide as a secretory product of mammalian cells. FASEB J 1992; 6: 3051-3064.

48. Brownlee $M$, Vlassara $H$, Kooney A, Ulrich $P$, Cerami A Aminoguanidine prevents diabetes-induced arterial wall protein cross-linking. Science 1986; 232: 1629-1632.

49. Cameron NE, Cotter MA, Dines K, Love A. Effects of aminoguanidine on peripheral nerve function and polyol pathway metabolites in streptozotocin-diabetic rats. Diabetologia 1992; 35: 946-950

50. Corbett JA, Tilton RG, Chang $\mathrm{K}$, et al. Aminoguanidine, a novel inhibitor of nitric oxide formation, prevents diabetic vascular dysfunction. Diabetes 1992; 41: 552-556.

51. Bradley J, Thomas PK, King RH, et al. Morphometry of endoneurial capilaries in diabetic sensory and autonomic neuropathy. Diabetologia 1990; 33: 611-618.

52. Jakobsen J. Axonal dwindling in early experimental diabetes. II. A study of isolated nerve fibres. Diabetologia 1976; 12: 547-553.

53. Mizisin AP, Powell HC. Schwann cell injury is attenuated by aldose reductase inhibition in galactose intoxication. Neuropathol Exp Neurol 1993; 52: 78-86. 